\title{
¿ES POSIBLE UNA ARQUEOLOGÍA SIN EXCAVACIÓN? \\ El caso de la Quebrada de Humahuaca en el contexto sudamericano
}

\author{
Mariel Alejandra López \\ CONICET, Instituto de Arqueología, Facultad de Filosofía y Letras, \\ Universidad de Buenos Aires \\ Clara Elisa Mancini \\ CONICET, Instituto de Arqueología, Facultad de Filosofía y Letras, \\ Universidad de Buenos Aires \\ Verónica Judith Acevedo \\ Instituto de Arqueología, Facultad de Filosofía y Letras, \\ Universidad de Buenos Aires
}

\begin{abstract}
Resumen: En este trabajo reflexionamos sobre la posibilidad de plantear una arqueología sin excavación en el escenario social, político y académico en el que se desarrolla un proyecto de investigación arqueológica, desde el año 2006 a la actualidad. Dicho proyecto está centrado en el estudio de los cambios sociales y materiales ocurridos luego de las conquistas incaica y española en el departamento de Humahuaca, Quebrada de Humahuaca, Jujuy, República Argentina. A partir de las tensiones generadas entre comunidades originarias, otros pobladores, instituciones locales y arqueólogos en el contexto sudamericano dentro del cual se enmarca nuestra región de estudios, así como de un conflicto puntual sucedido en el año 2012, analizamos aquí los procesos por los que están atravesando las comunidades, nuestra postura como arqueólogas y el lugar de la excavación dentro de la disciplina.
\end{abstract}

En el transcurso de esta última década, los escenarios políticos, sociales y académicos en los cuales se desarrollaron las investigaciones arqueológicas en Sudamérica en general, y en nuestra región de estudios en particular, se han modificado mucho. En especial, en relación con la aparición y la construcción de las concepciones sobre el patrimonio y el territorio.

Este trabajo ha sido posible en el marco de los trabajos de campo realizados gracias a un subsidio PIPCONICET 242 (2010-2012) titulado: “Variaciones temporales en la ocupación humana del umbral entre tierras altas y bajas. Arqueología de las nacientes de la Quebrada de Humahuaca". Nuestro agradecimiento a todos los amigos de las comunidades del departamento de Humahuaca quienes sumaron y colaboraron de distintas maneras con este trabajo, especialmente a Juan Lamas, vecino de Humahuaca y de Cianzo, y a Valentina García, vecina de Humahuaca y Calete, quienes nos aportaron "otras" miradas. Asimismo, agradecemos los interesantes comentarios aportados por los evaluadores. No obstante ello, la responsabilidad por el contenido es exclusivamente nuestra.

Latin American Research Review, Vol. 51, No. 4. (C) 2016 by the Latin American Studies Association. 
De acuerdo con algunos autores, uno de los principales factores que ha contribuido en forma decisiva a esta situación en nuestra región de estudios fue la declaratoria por parte de la Organización de las Naciones Unidas para la Educación, la Ciencia y la Cultura (UNESCO) en el año 2003 de la Quebrada de Humahuaca como Patrimonio de la Humanidad en la categoría de "Paisaje Cultural" (Troncoso 2009; Belli y Slavutsky 2010; Bergesio y Montial 2011; Salleras 2011). Sin embargo, no podemos dejar de lado el nuevo contexto sudamericano que posibilitó la creciente visibilización de quienes comenzaron a ser reconocidos como pueblos originarios. ${ }^{1}$ En efecto, y como consecuencia de ambos factores, consideramos que en estos últimos años las autopercepciones y categorizaciones externas de la identidad en Humahuaca se han visto altamente modificadas.

Debido a que estos nuevos procesos atraviesan directamente la práctica científica, siguiendo a de la Cadena (2005) y según nuestras propias experiencias, consideramos que revisar los aspectos que subyacen detrás de las etiquetas identitarias que operan actualmente en la región de estudios nos permite revelar muchos de los significados anteriormente suprimidos, develar las nuevas relaciones sociales que permitieron su aparición, así como comprender por qué actualmente existe un discurso que desalienta las excavaciones, en especial en aquellos sitios arqueológicos de origen prehispánico o donde habitaron los antiguos pobladores de la región. A estos sitios, restos materiales de ese pasado que es reelaborado desde el presente con distintos significados, política y académicamente se los identifica como patrimonio. Sin embargo, a nivel comunitario se los reconoce como propiedad privada o de la comunidad, donde aún hoy viven los apus, en relación con el concepto de territorio y dentro de una creciente autonomía de los pueblos originarios. $^{2}$

\section{LA QUEBRADA DE HUMAHUACA EN LA PERSPECTIVA SUDAMERICANA}

Según algunos especialistas, a partir del año 2003 con la gestión del presidente argentino Néstor Kirchner, favorecida a su vez por la emergencia de un polo latinoamericano visible en los gobiernos de centro-izquierda y en un contexto de cri-

1. El Estado nacional refiere a "pueblos originarios" de acuerdo con las nominaciones internacionales. Sin embargo, en los diferentes foros y congresos así como en normativas legales, también se refiere a ellos como "pueblos indígenas" u "originarios". Estos conceptos son políticamente estratégicos al implicar la autodeterminación y remarcar la pre-existencia. En Argentina en particular, y a partir de la Ley 23.302, también se refiere a ellos como "comunidades indígenas" en relación con las formas específicas de organización. El Instituto Nacional de Asuntos Indígenas (INAI) adhiere a esta última categoría ya que remite al hecho de que varias comunidades pueden formar parte de un mismo pueblo (Manasse y Arenas 2010b).

2. De acuerdo con el análisis de diversas fuentes, según Zecenarro Benavente (2003), el término apu ha sido comúnmente utilizado en el mundo andino para referir a grandes cerros y a los dioses tutelares pretéritos que componen la geografía sagrada. De modo similar, y hasta la actualidad, en la Quebrada de Humahuaca con dicho término se refiere tanto a los cerros que la rodean como a los dioses que los habitan. De acuerdo con una visión crítica de diversas posturas teóricas, para di Salvia (2011), en la cosmología andina la naturaleza llevaría implícito algo de vitalidad y es en este sentido que sería posible admitir que en los cerros viven los apus porque ellos serían algo así como los "espíritus" de las montañas que actúan sobre diversas instancias de la vida cotidiana. 


\section{Latin American Research Review}

sis y crítica del neoliberalismo, comenzaron a correrse las fronteras del conflicto social (Svampa 2008). En ese sentido, mientras que por un lado se reconfiguraron las organizaciones de desocupados y re-emergieron los conflictos sindicales, por el otro, explotaron los conflictos socio-ambientales y se visibilizaron las antiguas y nuevas luchas por la tierra y el territorio en la región. Siguiendo a esta autora, estos conflictos diseñaron una "cartografía de la resistencia" diferente a la de los años 90 pero en la que prevalecieron lenguajes de movilización pergeñados en aquella época: el uso de la acción directa, la expansión de la forma asamblea y la demanda de autonomía.

En el contexto mundial de la globalización y expansión del capitalismo sobre territorios antes marginales, sectores de Sudamérica que se encontraban aislados encuentran nueva relevancia bajo el paradigma del desarrollo. En el Noroeste argentino, la Quebrada de Humahuaca es uno de ellos. Como señalan Belli y Slavutsky (2009), este avance supone el despojo de los medios de producción, en especial la tierra, de los campesinos e indígenas. En ese marco, la patrimonialización, que promete preservar los recursos patrimoniales, junto con el crecimiento del turismo, que promete desarrollo de regiones marginales, han sido los instrumentos que permitieron el avance del capitalismo en la región (Almirón, Bertoncello y Troncoso 2006; Belli y Slavutsky 2009; Mancini y Tommei 2012).

Por otro lado, desde la década de los años 90, y más especialmente en los últimos años, se han generado diversas instituciones y mecanismos con el fin de garantizar los derechos de los pueblos originarios. No obstante, desde el punto de vista de algunos de los agentes que forman parte de las nuevas organizaciones locales — tales como el Consejo de Participación Indígena (CPI)—, la política nacional llevada a cabo por distintos organismos no cubre todas las expectativas o necesidades de las comunidades y sus representantes. ${ }^{3}$ Entre otros aspectos, así surgen una serie de contradicciones ya que mientras que los pueblos originarios o las comunidades reclaman al Estado nacional argentino subsidios o representación, por ejemplo a través del Instituto Nacional de Asuntos Indígenas (INAI), ${ }^{4}$ al mismo tiempo exigen autonomía en todas sus decisiones, incluyendo las que exceden el control de sus tierras, con el fin de volver al dominio de los territorios que históricamente les pertenecen.

A partir de estas transformaciones, se generaron nuevas relaciones entre los llamados agentes tradicionales y modernos, derivados de la yuxtaposición de universos de acción social que resulta en la constitución de territorios que presentan tensión social. Así, mientras que la tradición, la memoria y los símbolos de un

3. El CPI es un organismo del INAI formado por representantes que son elegidos por las comunidades aborígenes para ser parte, a su vez, del Consejo de Coordinación del INAI. La creación del CPI en el año 2004 en este ámbito constituye de este modo el inicio de un proceso de consulta y participación entre el Estado nacional argentino y los pueblos originarios ya que representa un espacio concebido para resolver todos los asuntos que afectan a dichos pueblos.

4. El INAI es para algunos autores una entidad estatal de tipo asistencialista (Barié 2003). Según el propio INAI, ellos son los encargados "de asegurar el ejercicio de la plena ciudadanía a los integrantes de los pueblos indígenas, garantizando el cumplimiento de los derechos consagrados constitucionalmente (Art. 75, Inc. 17)". 
pasado investido de sacralidad organizan la existencia, también son las prácticas modernas, el conocimiento especializado y la mercantilización de saberes quienes la definen (Lifschitz 2006).

Si observamos en perspectiva sudamericana la situación de las comunidades indígenas, es indudable que toda intervención arqueológica y antropológica no sólo se verá atravesada por los saberes y las prácticas que se generan desde la academia sino, también, por el contexto social y político en el cual se hallan inmersos los académicos y sus objetos de estudio. En el caso de las comunidades de la Quebrada de Humahuaca, y en particular, de las que forman parte del departamento de Humahuaca, ellas apelan a la autonomía de sus decisiones tanto al nivel de las comunidades locales, como al nivel de la comunidad general o nación Omaguaca. ${ }^{5}$ En este sentido, Lifschitz $(2006,68)$ señala que al contrario de lo esperado por el discurso de la globalización hay un movimiento inverso, que conforma lo que él llama "neocomunidades": "ao invés de participarem dos fluxos de desterritorialização e hibridação, as neocomunidades representam uma tendência à refundação de territórios tradicionais e à produção de 'autenticidades' culturais delimitadas espacial e simbolicamente".

En el caso de la Quebrada de Humahuaca este proceso se ha visto incentivado, a la vez que regulado, por el mismo Estado argentino en el reconocimiento oficial de comunidades indígenas. A su vez, estas designaciones generaron una nueva legitimidad de antiguos reclamos vinculados al acceso a la tierra y al territorio.

Por su parte, si analizamos los distintos discursos y prácticas de la academia, puede decirse que no hay intensiones científicas puras. En este sentido, actualmente se visualiza una lucha de poder dentro de sectores de la academia arqueológica, en particular en nuestro país lo hemos podido observar en el diálogo con colegas y en el marco de distintos eventos y reuniones científicas. Por un lado, están aquellos que abogan (más o menos conscientemente) por la formación, consolidación y reproducción de una burocracia científica que legitima las maneras correctas de hacer ciencia (en el sentido de Bourdieu [2003]), y por el otro, están los que cuestionan desde análisis más postcolonialistas ciertas prácticas científicas vigentes, en un intento de solidaridad con la postura de las comunidades o sus representantes. Cuando se asume esta última posición la práctica profesional se vuelve un ejercicio más reflexivo, crítico y pluralista, que permite que comiencen a circular otros relatos "dejando de lado el centralismo del saber universitario, preocupado por los resultados, más que por los procesos de producción del conocimiento" (Manasse y Arenas 2010a, 3; Lenton 2009). Es interesante notar que algunos de estos nuevos discursos y prácticas no proceden sólo del sistema académico, sino también de nuevos agentes sociales locales que aspiran a participar de eventos políticos, sociales y académicos haciendo más evidente la necesidad de vincular la práctica arqueológica con el presente y el futuro de las comunidades originarias.

Desde mediados del siglo XX, y más frecuentemente desde 1980, se ha reali-

5. El departamento de Humahuaca posee un total de cuarenta y nueve comunidades locales reconocidas como tales. 
zado desde la antropología una crítica de su relación con la colonialidad, resaltando los aspectos políticos, económicos e ideológicos del colonialismo. Luego de las primeras críticas a la vinculación en sus orígenes con los intereses coloniales, la reacción poscolonial de la disciplina ha incorporado poco a poco una crítica a los aspectos epistémicos, revisando como lo epistémico y lo colonial se constituyen mutuamente (Restrepo 2007). Así, mientras que la antropología comenzaba su inclusión de la diversidad cultural, la arqueología en su mayoría seguía excluyendo y negando otras formas de conocimiento histórico, a través de la determinación de lo que es científico y lo que no lo es. De este modo, la arqueología se auto-proclamaba "científica", a través de mejoras en sus procedimientos de campo y sus métodos clasificatorios (Gnecco 1999). Aun así, como parte de una reacción poscolonial más amplia, la arqueología comenzó un diálogo con las comunidades indígenas desde hace más de treinta años y ha debido enfrentar sus propias críticas, acusada de ser colonialista, racista e imperialista (Allen y Phillips 2010).

Esta nueva situación se hizo específicamente evidente en la arqueología con la llegada del multiculturalismo, que abrió necesariamente la participación a la diversidad que los nacionalismos negaban (Gnecco y Ayala 2010). En efecto, tradicionalmente la arqueología utilizó la historia indígena como parte del relato de origen de comunidad imaginada (en el sentido de Anderson [1993]). Para algunos autores, esa apropiación, bajo la forma actual de patrimonio, constituyó y constituye aún un modo de violencia que ejerce la disciplina sobre las comunidades originarias o indígenas (Haber 2011; Gnecco y Ayala 2010).

De este modo, esta reflexión sobre la relación con las comunidades indígenas que la disciplina ha comenzado en el contexto sudamericano (ej., Gnecco 1999; Endere 2000; Uribe Rodríguez y Adán Alfaro 2003; Aschero et al. 2005; Hernández Llosas et al. 2010; Otero, Montenegro y Rivolta 2011) de ningún modo se ha resuelto ni representa el pensamiento mayoritario de los arqueólogos. Por ello, y a partir de una situación concreta, consideramos en nuestro análisis las nociones de patrimonio y territorio ya que tratamos de observar no sólo lo que estos conceptos significan en un contexto teórico o aparentemente despojado de intereses económicos y políticos, sino también cómo significan o resignifican los contextos en los cuales ellos se aplican, transformándose muchas veces en herramientas manipuladas para alcanzar objetivos generalmente contrapuestos.

\section{LAS ETIQUETAS ÉTNICAS, EL TERRITORIO Y}

\section{LA AUTONOMÍA VERSUS EL PATRIMONIO}

En el contexto político, social y académico antes señalado, y como arqueólogas, en el transcurso de estos últimos años hemos podido observar las distintas formas en que algunas etiquetas identitarias y algunos conceptos se han ido modificando.

En efecto, en primer lugar notamos que no hace mucho más que diez años atrás la mayoría de los habitantes de la Quebrada de Humahuaca optaban por definirse como criollos al estilo del mestizo y no indígena que caracterizó, por ejemplo, parte de la historia sudamericana (de la Cadena 2005), y/o directamente como 
descendientes de los europeos que colonizaron la región. ${ }^{6}$ No obstante, generalmente no se definían como blancos, tal como sí aparentemente sucedía en Perú.

En la última década gran parte de los pobladores de la Quebrada de Humahuaca han comenzado a reconocerse como descendientes de los pueblos indígenas e, incluso muchos de ellos, a auto-etiquetarse según antiguos nombres étnicos, teóricamente referidos a las etnias identificadas por los españoles llegados a fines del siglo XVI a la región de estudios.

Este auto-reconocimiento fue posible, sobre todo a partir de mediados del siglo $X X$, como consecuencia de la difusión y conocimiento de diversos trabajos académicos que aportaron un importante repertorio de información respecto de estos nombres y de la situación en la que se encontraban las comunidades indígenas al momento de la conquista y colonización temprana en la región (entre los principales autores, ver Carrillo [1877] 1989; Serrano 1930; Casanova 1944; Salas 1945; Canals Frau 1953; Vergara 1961; Sánchez y Sica 1992; Sánchez 2004; Zanolli 2005).

En este sentido también encontramos que a partir de la apertura que posibilitó el contexto sudamericano de los últimos gobiernos de turno en toda la región y del reconocimiento de los pueblos originarios o comunidades indígenas desde las diversas instituciones estatales o nacionales, se activó un reacomodo identitario de dichas comunidades. En el caso de la Quebrada de Humahuaca este proceso aún se encuentra en pleno desarrollo entre los pobladores. Dentro de este proceso también es posible observar que individuos que por su color de piel o lugar de origen antes eran llamados gringos o blancos (por ser extranjeros o procedentes de las principales ciudades del país), actualmente se consideran parte de alguna de las comunidades mediante un proceso de adscripción cultural (de la Cadena 2005) que tiene antecedentes históricos en la región de estudios como un recurso en tiempos de crisis (ver, por ejemplo, López 2006).

De acuerdo con Lifschitz $(2006,68)$, estas comunidades son reconstruidas sobre el patrimonio y la memoria, pero a través de agentes modernos (tales como organizaciones no gubernamentales, los medios masivos de comunicación, entre otros) que promueven una reconstrucción de territorios y saberes desde dispositivos modernos que se necesitan mutuamente: "Por um lado, as instituições externas, que representam a modernidade, precisam da tradição comunitária para viabilizar seus projetos e para gerar novos recursos vinculados ao patrimônio material e imaterial. Por outro, a comunidade, que representa a tradição, precisa das instituições externas para projetar seu valor, tanto no sentido simbólico quanto no material".

En segundo lugar, observamos que las comunidades de la región han comenzado a reivindicar el acceso a la tierra bajo el reclamo de territorio. En este sentido recordamos que, mientras la tierra suele identificarse con el espacio estrictamente

6. La primera autora recuerda que desde el inicio de sus trabajos allá por los años 90 en la región fue precisamente su apellido lo que generaba mayor empatía con las poblaciones locales. Generalmente todos ellos reconocían algún ancestro europeo entre sus abuelos o bisabuelos, marcando ello una distancia social con los indios y una mayor cercanía, a modo de ascenso social, con los blancos. Esta construcción identitaria se corresponde con un imaginario nacional que sostenía que "los argentinos descendieron de los barcos". 
productivo de labranza, recolección o pastoreo, el territorio es el espacio que suele ser reivindicado como propio ya que "adquiere sentido en tanto es vivido - desde adentro- como relación con el espacio: relación práctica, económica, histórica familiar, cultural, simbólica y ancestral aunque no siempre política" (Manasse y Arenas 2010b, 25). Este cambio desde el reclamo de tierras al de territorios también puede ser leído, tal como señalan algunos autores (ej., Rivolta y Montenegro 2009), como un efecto postcolonial producto de la manipulación de la información histórica, arqueológica y antropológica, tanto por parte de las comunidades o pueblos originarios como por parte de la academia misma.

En efecto, si consideramos al concepto de territorio como un producto de relaciones de dominación en donde se da un proceso de apropiación del espacio y como un continuum que va desde la dominación política y económica más concreta a la apropiación cultural y simbólica (en el sentido de López, Mancini y Nacht 2011a) es indudable que el devenir de nuestra propia disciplina también ha influido en las reivindicaciones que el uso de dicho concepto supone en el escenario actual. De este modo, mientras que las comunidades indígenas manipulan el concepto de territorio, el de sitio arqueológico o cultura material en pos de sus reclamos o reivindicaciones, desde la academia se manipula el pasado (material o inmaterial), reconstruido y presentado desde el presente como aquello que merece ser conocido, destacado y estudiado. Todo ello es lo que connota el concepto de patrimonio y constituye lo que se presenta como el legado que identifica a una comunidad.

En la arena de las negociaciones sobre el pasado que se dan entre la academia y las comunidades originarias, el patrimonio es entonces un recurso que continúa reproduciendo diferencias sociales, en el que los sectores hegemónicos logran producir y distribuir este tipo particular de bienes (García Canclini 1999). Los expertos o académicos forman así parte de un campo de producción de bienes culturales patrimoniales que, como cualquier campo (en el sentido de Pierre Bourdieu [1990]) no está aislado de la dimensión política. A su vez, un científico siempre busca realizar investigaciones de lo que considera importante, y en este sentido, la tendencia de los investigadores a centrarse sobre los temas que más interesan académica y políticamente se debe a que un aporte o descubrimiento en ese ámbito le significará mayor beneficio simbólico (Bourdieu 2003). De este modo, un tema de investigación es de interés legítimo cuando los científicos lo reconocen como tal porque se inscribe en la lógica del campo y en sus disposiciones históricamente constituidas. De hecho, es el interés del investigador el que exista un problema de investigación que, por otro lado, justifica su existencia. Así, separamos al problema del investigador, "como si fuese la enunciación (la nuestra) del problema la que nos habilitase a recorrer la investigación" (Haber 2011, 6).

A pesar de la academia, y desde hace algunos años con la reivindicación de la diversidad de voces sobre el pasado, la situación se ha vuelto algo más compleja. En efecto, la arqueología se ha visto interpelada y hasta, en algunos casos, forzada a cambiar (Allen y Phillips 2010; Haber 2011) debido a que, por ejemplo, algunos miembros de los pueblos originarios comenzaron a reivindicar como herencia de su pasado restos antes considerados sólo arqueológicos. En consecuencia, los restos arqueológicos pasaron a ser manipulados estratégicamente a favor de las 
distintas luchas que las comunidades indígenas han comenzado a llevar a cabo, entre ellas: la obtención de tierras, territorios y autonomía. Este último es un reclamo que, particularmente en nuestra región de estudios, ha sido fuertemente influido desde Bolivia (ver, por ejemplo, Chávez León 2008; Canessa 2012) y es el que permite a las comunidades tomar cierta distancia de las imposiciones de organizaciones supra comunitarias, incluso de los distintos poderes reconocidos por el Estado: la policía, el gobierno provincial y el nacional.

En medio de las distintas posturas y miradas sobre los restos o sitios arqueológicos, considerados ya sea como objeto de estudio, ya sea como patrimonio, ya sea como legado del pasado o como presente mismo, es interesante resaltar que en el reconocimiento de un otro (étnico, social, político, nacional, extranjero, colonialista) opera un doble imaginario, un "imaginario asimétrico" (Rosaldo 2011), que provoca nuevos conflictos entre los miembros de los autodenominados pueblos originarios con los investigadores, en este caso nosotras. Cuando esta asimetría queda en evidencia constituye un obstáculo difícil de superar ya que recuerda y expone la desigualdad dificultando el intercambio y el acuerdo. Por ello es que en este sentido, y en este momento, se vuelve una prioridad la reflexión sobre nuestro rol y más ampliamente el rol de la excavación arqueológica, en especial luego de un episodio ocurrido durante el último trabajo de campo llevado a cabo en el mes de octubre de 2012.

\section{¿ES POSIBLE UNA ARQUEOLOGÍA SIN EXCAVACIÓN?}

En el año 2012 iniciamos una campaña arqueológica en Calete (Quebrada de Humahuaca) a un mes de un público hecho de violencia en Humahuaca, en donde sus habitantes se enfrentaron por la intención de usurpación de tierras de un grupo político venido de San Salvador de Jujuy, capital de la provincia de Jujuy (Agrupación del Titi Guerra, ala desprendida del grupo liderado por Milagro Salas). Como resultado de ello, se quemaron varios vehículos, hubo heridos y, lo más grave, murió un joven humahuaqueño que defendía sus tierras.

Contábamos entonces con los permisos y papeles provinciales y comunales necesarios para trabajar en dos sitios arqueológicos. Sin embargo, a poco de iniciar el trabajo de campo en el Pukará de Calete, el nuevo representante político por el CPI de las comunidades de Humahuaca, A. Y,7 junto a unos pocos individuos más, nos echó del centro comunitario donde nos alojaba la comunidad de Calete, prohibiéndonos excavar el sitio bajo una variedad de argumentos que se resumen en los siguientes:

- Los arqueólogos se llevan muchos materiales que no devuelven nunca más y, si lo hacen, no se los devuelven a ellos, sus verdaderos dueños.

- Si excavan, los arqueólogos deberían poder analizar todo en el campo, in situ, tal como, según ellos, hacen colegas extranjeros.

- Los sitios arqueológicos son de propiedad privada o comunitaria.

7. Este representante asumió en abril de 2011, cuando aún estábamos finalizando el trabajo de campo anterior. Aunque se trata de un personaje público, por cuestiones de confidencialidad resguardamos su nombre y apellido utilizando sus iniciales. 
- En los sitios arqueológicos viven los apus y hay que respetarlos.

- Los sitios arqueológicos se han llevado (han matado) ya a varios arqueólogos por intentar excavarlos.

- No es necesario que los arqueólogos estudien para luego decir qué fue lo que pasó con sus abuelos, sus ancestros.

El episodio narrado, violento por las amenazas y amedrentamientos recibidos hasta que salimos del departamento de Humahuaca, desencadenó una serie de interrogantes que de un modo u otro ya nos veníamos haciendo en las instancias previas de investigación (trabajo en archivos documentales y observaciones actualísticas). Entre ellos, nos preguntamos si era posible hacer una arqueología sin excavación; de ser así, cómo reformular el rol tradicional del arqueólogo, en especial, dentro del sistema académico dominante y si esto sería simplemente un problema teórico, metodológico o de otra índole.

De acuerdo con nuestra experiencia de investigación en la región desde el año 2006 en adelante, y en términos de alcanzar muchos de los objetivos propuestos en nuestro proyecto marco, observamos que hasta ese momento no sólo había sido posible investigar sin excavar sino, también, en cierto modo esto había sido así programado. Dicho proceder obedeció no sólo a comenzar con una reconstrucción no invasiva sino, además, porque la dinámica social previa también así ya lo exigía ya que, además del permiso provincial, fue preciso contar con el consenso de la mayoría de las comunidades para iniciar una investigación en la micro región de estudios. De este modo, y desde un comienzo, hemos dado un lugar destacado al trabajo con miembros de las comunidades o pueblos originarios, especialmente aquellos que viven en torno a los sitios arqueológicos, visibilizando también de este modo las distintas voces que fuimos escuchando, no sólo desde pares o colegas locales sino, también, desde los intereses, dichos y manifestaciones de distintos miembros que vieron con interés la posibilidad que nuestro estudio les brindaba para reconstruir una historia aún no contada y que, desde luego, les permitiría reclamar con más argumentos las tierras o territorios que ocupan.

Sin embargo, luego del episodio del año 2012, justo cuando íbamos a comenzar con la etapa de excavaciones, y frente al panorama de diversidad de conflictos actuales, resultó claro que no podíamos dar comienzo a las excavaciones que habíamos programado. De hecho, otros arqueólogos también debieron suspender este tipo de actividades en otros sitios arqueológicos del mismo departamento. En el "imaginario asimétrico" (Rosaldo 2011) de los pueblos originarios de nuestra región de estudios, o al menos en algunas de sus voces retomadas por el actual representante general y político, el sitio arqueológico se convirtió en un recurso cultural que debían defender frente a los investigadores, a quienes vinculan con un otro extranjero, colonialista y capitalista. Y lo más importante, en la medida en que sostienen que este recurso cultural, el sitio arqueológico, les pertenece por estar dentro de sus tierras (privadas o comunitarias), también luchan por sus territorios y autonomía.

Desde la década de los años 1980 en adelante ha habido numerosas normativas relacionadas al patrimonio tanto a nivel nacional, como provincial y local, que fueron de la mano de un incipiente turismo cultural, que ha aumentado exponen- 
cialmente desde el año 2000 en adelante (Troncoso 2009). ${ }^{8}$ De acuerdo con algunos investigadores, este escenario entraña un riesgo de mercantilización de la cultura, reproducción de la colonialidad y hasta de discriminación en áreas rurales (Cruz 2010; Lombardo 2010; Haber 2011) en donde el motor de este proceso es el auge del turismo por un lado y la declaratoria de la UNESCO por el otro (ver, entre otros, Belli y Slavutsky 2010).

Si reparamos en estas observaciones, nuestros interrogantes cobran sentido no sólo desde lo teórico y metodológico que implica la perspectiva académica del problema, sino también desde los planteos éticos. En efecto, y por citar un ejemplo, por ley es posible excavar con presencia policial ya que se la considera fuerza de aplicación de la ley de patrimonio en casos como el que nos ha tocado vivir en el año 2012. En efecto, frente a episodios como el mencionado en este trabajo, ésta había sido una propuesta concreta que nos hizo un abogado cuando hace algunos años atrás le consultamos, precisamente, sobre hasta dónde podíamos insistir con las comunidades con la etapa de excavación a fin de avanzar en las investigaciones en un contexto sociopolítico como el de Humahuaca, que ya se avecinaba conflictivo con respecto a este tema. Lo interesante es que ésta no sólo fue la postura que nos indicaban seguir desde el costado más académico y legal sino también la de la propia policía de Humahuaca una vez instalado el conflicto a partir del episodio del año 2012.

Tal como señalamos anteriormente, dadas las circunstancias, nuestra investigación ya venía desarrollándose con la prescindencia de la excavación propiamente dicha y a fin de evitar el conflicto, mediante la construcción de otras herramientas teórico-metodológicas. En este sentido, además de "excavar" en documentos, como arqueólogos, llevamos a cabo una serie de trabajos de arqueología etnográfica, en base a la realización de distintas observaciones actualísticas.

No obstante ello, de acuerdo con la visión más decimonónica de la arqueología aún instalada en gran parte del imaginario de nuestro ámbito académico y que nos llevó a plantear que parte del problema principal de investigación debía ser resuelto mediante la excavación de determinados sitios, en este caso, prehispánicos, llegamos al momento en el cual planteamos la excavación en un par de ellos, en un escenario de consenso con las dos pequeñas comunidades involucradas por estar asentadas en sus inmediaciones. En este sentido, la devolución de resultados preliminares a dichas comunidades, básicamente los realizados en base al análisis de documentación inédita de la región y en base a estudios actualísticos con cultura material vinculada a lo andino y a lo católico-europeo, fue clave en dicho consenso. Como consecuencia de todo ello, no sólo fue impensado el conflicto sino, también, el hecho de tener que recurrir a la fuerza de aplicación de la ley para poder dar inicio a las excavaciones.

De acuerdo con los planteos existentes sobre las diferentes aristas que poseen los procesos identitarios de nuestra región de estudio (étnica, de clase, entre las principales) que, por estos momentos aún revueltos, cuestionan prácticamente todos los ámbitos vinculados a las instituciones identificadas con el colonialismo y

8. Ver Mancini (2011) para un desarrollo de las normativas sobre el patrimonio en la Quebrada. 


\section{Latin American Research Review}

entre las cuales se encuentran nuestras disciplinas, la antropología y la arqueología, es que volvemos a preguntarnos y a preguntar a la academia si era posible plantear una arqueología sin excavación. Así, cuando extendimos este interrogante a muchos de nuestros colegas pudimos observar una variedad de respuestas que no hacen más que reflejar la multiplicidad de paradigmas o de modelos que aún coexisten en la antropología y la arqueología argentina. Y en este sentido, podemos decir que esto es síntoma de una crisis que algunos arqueólogos vienen poniendo de manifiesto desde los años 90 a través de su producción (ver, por ejemplo, Haber y Scribano 1993). En efecto, dentro del relevamiento efectuado entre nuestros colegas más próximos por amistad y/o lugar de trabajo encontramos que mientras algunos nos recomendaban dar un giro al proyecto, otros nos sugerían reformular ciertos objetivos y/o crear nuevos, mientras los más, al igual que muchos miembros de las comunidades, nos decían que no abandonáramos ni el proyecto ni la región de estudio.

Por la propia lógica de los campos, en el sentido que define Bourdieu (2003), se nos ha brindado un tipo de apoyo que podríamos denominar "gremial", pero también se nos ha señalado desde altas esferas del ámbito académico que sin excavación no había proyecto arqueológico posible, ubicando todo el peso de la legitimidad del conocimiento en dicha actividad, tal como lo señalaba el imaginario decimonónico de la arqueología. No obstante ello, considerando las distintas manifestaciones y procesos actuales que posibilitan que frente al conflicto suscitado en el último trabajo de campo podamos seguir revisando nuestro rol como arqueólogas dentro del grupo de investigación, y siguiendo planteos del tipo de los ya expresados por otros investigadores de la región (ej., Rivolta y Montenegro 2009), sostenemos que en esta etapa transitoria en donde no es posible excavar en algunos sitios es posible seguir investigando el pasado. Por ejemplo, mediante parte de la materialidad utilizada en reformulaciones (materiales y funcionales o ambas) en el presente, así como mediante el desarrollo de nuevas líneas de análisis que permitan extraer nueva información sobre materiales excavados en otra época y que actualmente se acumulan en los depósitos de los museos, sin más indicaciones que un catálogo de ingreso a la colección o, en el mejor de los casos, con la publicación descriptiva de sus principales características formales y decorativas.

\section{CONSIDERACIONES FINALES}

Desde nuestra perspectiva de análisis, el pasado siempre se construye desde el presente aunque no de manera lineal (Acevedo et al. 2009; López, Acevedo y Mancini 2010; López, Mancini y Nacht 2011a, 2011b). Por ello, este actual proceso de reconfiguración de las identidades también es posible vincularlo al proceso de construcción del conocimiento del pasado que estamos investigando y a las estrategias utilizadas por las comunidades de estos pueblos originarios (Sica y Zanolli 2010) para reclamar por sus tierras y recursos (Manasse y Arenas 2010b).

Pero, ¿qué nos dicen este proceso y el conflicto por la excavación de los sitios de la propia disciplina? En ningún momento habíamos considerado que nuestro proyecto formara parte de los mismos discursos colonialistas a los que se oponen 
los representantes políticos actuales de algunas de las comunidades más organizadas del Noroeste argentino. De hecho, parte de nuestro trabajo previo con las comunidades había sido el de tratar de establecer la continuidad histórica en el territorio de forma tal de apoyar la legitimidad del reclamo territorial así como aportar herramientas para el desarrollo del turismo rural, en base a los pedidos concretos de los líderes de un par de las comunidades del departamento de $\mathrm{Hu}$ mahuaca. Es decir que, aunque nuestro proyecto nació y se diseñó desde la academia, de acuerdo con un diseño que incluía a la excavación como modo de obtener datos del pasado que de otro modo no era posible conseguir, también consideró la situación social y política actual introduciendo nuevos objetivos y hasta un proyecto especial de divulgación de la información a fin de que ésta fuera sistemáticamente realizada. Aún así, en octubre de 2012 se expuso la "herida colonial" (Mignolo 2008) de la relación con las comunidades originarias, impulsándonos a una mirada introspectiva de lo que allí se ponía en juego para nosotras, no sólo como profesionales sino, también, como sujetos. ${ }^{9}$

A modo de cierre de este trabajo, nos gustaría dejar algunos ejes de discusión sobre la disciplina y su metodología planteados a partir de este caso concreto. En primer lugar, compartimos con Haber (2011) que el problema de investigación partió de nuestros intereses y, en este sentido nos ubicamos en un escenario de disputas en el que las comunidades reclamaron su lugar. Así, el mismo problema que nos justificó como investigadores, legitimó nuestro accionar y nos dio la posibilidad de llevar adelante un proyecto financiado por organismos estatales, fue cuestionado por el máximo representante político de las comunidades de Humahuaca, aunque no así por los líderes y miembros de las comunidades en cuestión. En medio de dicho enfrentamiento, nuestra posición ha sido casi instintivamente la de establecernos como las encargadas de restituir una historia no escrita, aunque esa legitimidad fuese también cuestionada por dicho representante: "nosotros no necesitamos que vengan a decirnos lo que ya sabemos, lo que pasó con nuestros abuelos".

En segundo lugar, el enfrentamiento nos dejó frente a la pregunta sobre nuestro nuevo rol. Previo a este suceso conflictivo creíamos tener una postura tomada, al servicio de la academia pero, también, al de algunos de los objetivos de las comunidades. Sin embargo, frente al conflicto, nuestra idea de comunidad se desmoronó haciéndose evidente que la comunidad no es un todo homogéneo, ni de intenciones desinteresadas, sino que opera como cualquier otro colectivo, en el que también intervienen mecanismos de la promoción individual de algunos de sus sujetos. En efecto, luego del enfrentamiento de los ciudadanos de Humahuaca con la agrupación Titi Guerra por unas tierras, nuestra expulsión del departamento de Humahuaca implicaba un mensaje similar a través de una expresión del representante político: "las comunidades no están de acuerdo con que entren

9. El concepto proviene de Gloria Anzaldúa, y según Mignolo (2005) es allí desde donde se desarrolla el pensamiento "des-colonial," posibilita así libertad de pensamiento y formas de vida. Esta apertura "reintroduce lenguas, memorias, economías, organizaciones sociales, subjetividades al menos doble: el esplendor y las miserias de los legados imperiales, y la huella imborrable de lo que existía convertida en herida colonial; en la degradación de la humanidad, en la inferioridad de los paganos, los primitivos, los subdesarrollados, los no-democráticos" (Mignolo 2005, 26, el énfasis es nuestro). 


\section{Latin American Research Review}

a su territorio por la ventana . . acá sin permiso de nadie, vienen se meten y no es así" (A.Y., en la radio Luna Azul). En este sentido, quedamos inmersas en un contexto de revuelo político y creemos que nuestra expulsión formó parte de un mecanismo de promoción individual, pero aún así, la justificación del hecho debe ser escuchada.

En tercer lugar, y a nivel más amplio, el conflicto nos llevó a reflexionar qué implica la excavación dentro de la arqueología. Aquí resaltamos uno de los puntos centrales de la justificación del campo (Bourdieu 1990, 2003), lo que nos ha quedado claro aún en nuestra propia reacción cuando explicamos a dicho representante político que "el registro material es la única forma de demostrar la continuidad de las comunidades en el territorio" y también en la de otros colegas que demostraron su preocupación sobre la posibilidad de no poder continuar con una investigación sin excavación, incluso desde las instituciones que nos señalaron la misma inquietud.

Ahora bien, es interesante notar aquí que el rol central o no de la excavación dependerá del problema planteado y/o de su formulación. En ese sentido, dentro del ámbito académico excavar o no excavar puede tener que ver más con un problema metodológico aunque también ello conlleve una justificación teórica. De hecho, parte de nuestro trabajo de investigación previo bajo el problema de estudio formulado inicialmente ha justificado la no excavación mediante el análisis de otras líneas de evidencias, entre ellas las documentales, los estudios actualísticos y los análisis de materiales de colección.

De acuerdo con algunas miradas locales la excavación es una nueva invasión, es como entrar a sus casas sin invitación, "por la ventana", y una expropiación, ya que según ellos los arqueólogos "dicen nosotros no venimos a huaquear ... ¿ pero a qué es lo que vienen? Si ellos han hecho excavación, han venido a huaquear directamente" (A.Y., en la radio Luna Azul). ${ }^{10}$ En estos sentidos, es interesante notar que en la mayoría de los discursos se resalta el rol del arqueólogo como agente del Estado argentino y con poder de policía sobre el patrimonio antes que la postura del arqueólogo de parte que creímos asumir en algunos casos en que, además, las comunidades locales se interesaron por la investigación que les propusimos, incluyendo excavaciones. Al respecto es importante destacar que si bien nunca fue nuestra intención utilizarla, nos fue ofrecida la policía para poder llevar adelante la excavación que quisimos iniciar, por lo que este enfrentamiento no hizo más que desnudar parte de la relación conflictiva que también está instalada entre las comunidades y las autoridades de toda índole del gobierno provincial.

Finalmente, la "huella de la herida colonial" se nos ha hecho evidente hasta en algunas sutilezas. En varios momentos de las conversaciones que mantuvimos con el representante político que cuestionó las tareas de excavación notamos que mientras nosotras hacíamos referencia al Pukará de Calete, él nos corregía señalándonos que ese no era un Pukará sino un Antigal, poniendo de relieve la importancia del conocimiento local por sobre el académico y marcando las diferencias,

10. Huaquear es un término indígena utilizado históricamente en época colonial para referir al rescate de las huacas o antiguos entierros frente al español. En la actualidad es sinónimo de robo. 
las diferencias heredadas e históricamente inevitables (de la Cadena 1998) que caracterizaron la historia de la aparente supremacía de la educación.

Indudablemente, es en muchas de las prácticas y materialidades contemporáneas, en especial las de naturaleza ritual (ver, por ejemplo, López, Acevedo y Mancini 2010; López 2012), que enraíza lo que actualmente se identifica como Nación Omaguaca. Sin embargo, con esta nueva etiqueta identitaria se busca algo más que reconocerse como herederos naturales de los antiguos pobladores de la región, con ella se pone de manifiesto el nuevo orden social y político en el que se encuentran las comunidades.

Siguiendo a de la Cadena (2005), las etiquetas identitarias pueden contener múltiples significados y cambiar a través del tiempo. En efecto, actualmente bajo el rótulo de Nación Omaguaca, y a través de recursos culturales que incluyen materialidades visibilizadas a través de imágenes objetuales o lingüísticas, no sólo se intenta desacreditar la autoridad de los científicos que anteriormente los pusieron en contacto con las etiquetas étnicas de la región en tiempos post conquista (los Humahuaca, los Tilcara, entre los principales), sino además se connota una nueva situación social, política y económica que les permite reclamar territorio y autonomía, nociones que habían sido silenciadas en los escenarios previos al nuevo panorama político y social sudamericano y argentino.

En este contexto particular en donde renacen reclamos que son históricamente rastreables (López, Mancini y Nacht 2011b) y las numerosas comunidades de Humahuaca han logrado un nuevo status y una mejor representación bajo la etiqueta de Nación Omaguaca (un colectivo políticamente organizado y movilizado para enfrentar a los distintos poderes hegemónicos) la práctica de la excavación, reglada según normas que son actualmente rechazadas por las comunidades, es interpretada como un robo y, en consecuencia, como una actitud provocadora frente a las nuevas posibilidades de acción y decisión política que el mismo sistema nacional que nos extiende los permisos de excavación ofrece a las comunidades originarias. En este sentido, estos momentos y seguramente los años por venir, serán tiempos de reflexión sobre nuestra postulación de los problemas a investigar y sobre la práctica profesional en la arqueología argentina contemporánea.

Según algunos de los cuestionamientos a la postura colonialista de la disciplina es la "coartada del conocimiento" y su "carácter hegemónico", así como la metodología disciplinar, lo que nos hace partícipes de la violencia que implica separar las relaciones del conocimiento de las relaciones sociales (Haber 2011). En este escenario de cuestionamiento disciplinar y siguiendo a este autor nos preguntamos entonces ¿será necesaria la excavación de un sitio que es considerado sagrado o simplemente privado para otros ("violentando la violencia simbólica colonial" que lo consideró arqueológico y patrimonio de la humanidad), a fin de resolver un modelo teórico o un problema planteado por nosotras de acuerdo con un protocolo metodológico disciplinar? Y, mejor aún, considerar al otro y sus conocimientos en nuestra práctica profesional ¿será entonces sólo un tema del plano de lo moral o lo políticamente correcto?, ¿o será necesario a las relaciones sociales que debemos entablar en el proceso de conocimiento?

Finalmente, consideramos que esta puede constituir una etapa transitoria en 


\section{Latin American Research Review}

la región de estudios que hemos presentado, tal vez de las más conflictivas para la arqueología argentina. Por el momento sostenemos, lo mismo que otros colegas, que es preciso aguardar el tiempo que sea necesario a las comunidades para poder seguir avanzando en la reconstrucción de sus historias mediante la excavación. Y, para comenzar una nueva etapa, debemos asegurar la participación de las comunidades y sus intereses desde el diseño hasta los resultados de la investigación.

\section{REFERENCIAS}

Acevedo, Verónica J., Ana L. Espinoza, Mariel A. López y Clara E. Mancini

2009 "La feria de las Alasitas de Parque Avellaneda, ciudad de Buenos Aires, y sus vinculaciones con la tradición andina de miniaturas". En Buenos Aires boliviana: Migración, construcciones identitarias y memoria, editado por Leticia Maronese, 249-265. Buenos Aires: Comisión para la Preservación del Patrimonio Histórico Cultural de la Ciudad de Buenos Aires.

Allen, Harry, y Caroline Phillips

2010 "Maintaining the Dialogue: Archaeology, Cultural Heritage and Indigenous Communities". En Bridging the Divide: Indigenous Communities and Archaeology into the 21st Century, editado por Harry Allen y Caroline Phillips. Walnut Creek, CA: Left Coast Press.

Almirón, Analía, Rodolfo Bertoncello, y Claudia Troncoso

2006 "Turismo, patrimonio y territorio: Una discusión de sus relaciones a partir de casos de Argentina". Estudios y Perspectivas en Turismo 15: 101-120.

Anderson, Benedict

1993 Comunidades imaginadas. Buenos Aires: Fondo de Cultura Económica.

Aschero, Carlos A., Victor H. Ataliva, M. Lorena Cohen, Sara M. López Campeny y Carolina Somonte

2005 "Arqueología e identidad ... o identidad de la arqueología en la comunidad indígena de Amaicha del Valle (Tucumán, Argentina)". Revista Textos Antropológicos 15: $263-276$.

Barié, Cletus G.

2003 Pueblos indígenas y derechos constitucionales en América Latina: Un panorama. La Paz, Bolivia: Génesis.

Belli, Elena, y Ricardo Slavutsky

2009 "Tierra y producción simbólica: Las condiciones materiales del patrimonio". En Actas del X Congreso Argentino de Antropología Social, editado por la Facultad de Humanidades y Ciencias Sociales. Posadas, Argentina: Universidad Nacional de Misiones. http://www.scielo.org.ar/pdf/ava/n14/n14a13.pdf.

2010 "Gestiones patrimoniales y prácticas profesionales". En Arqueología, tierras y territorios: Conflictos e intereses, compilado por Bárbara Manasse y Patricia Arenas, 143-163. Tucumán, Argentina: Lucrecia Editorial.

Bergesio, Liliana, y Jorge Montial

2011 Lo que la declaratoria nos dejó: Turismo, patrimonio y desarrollo en la quebrada de Humahuaca desde la perspectiva de sus pobladores. Misiones, Argentina: Centro de Estudios Sociales (CES), Universidad Nacional del Nordeste (UNNE) y Asociación Latinoamericana de Sociología (Alas). http://ces.unne.edu.ar/prealas/eje2/bloque4/ BergesioMontial.pdf.

Bourdieu, Pierre

1990 Sociología y cultura. México, DF: Grijalbo.

2003 Intelectuales, política y poder. Buenos Aires: Eudeba.

Canals Frau, Salvador

1953 Las poblaciones indígenas de la Argentina: Su origen, su pasado, su presente. Buenos Aires: Sudamericana. 
Canessa, Andrew

2012 "De la arqueología a la autonomía: El uso de restos precolombinos para forjar una nueva relación con el Estado en Bolivia". Nuevo Mundo Mundos Nuevos. http://nuevo mundo.revues.org/64577.

Carrillo, Joaquín

(1877) 1989 Jujui: Provincia Federal Arjentina. Apuntes de su historia civil (con muchos documentos). San Salvador de Jujuy, Argentina: Universidad Nacional de Jujuy.

Casanova, Eduardo

1944 La Quebrada de Humahuaca. Buenos Aires: ACA, Guía de Viaje (Noroeste).

Chávez León, Marxa N.

2008 "'Autonomías indígenas' y 'Estado Plurinacional': Proyectos políticos de los movimientos indígenas y campesinos en Bolivia". OSAL 9 (24): 51-71.

Cruz, Pablo

2010 "Abarcas campesinas y momias for export: Identidad, cultura y negocio en el Salar de Uyuni (Bolivia)". En Arqueología, tierras y territorios: Conflictos e intereses, compilado por Bárbara Manasse y Patricia Arenas, 111-142. Tucumán, Argentina: Lucrecia Editorial.

de la Cadena, Marisol

1998 "Silent Racism and Intellectual Superiority in Peru". Bulletin of Latin American Research 17 (2): 143-164.

2005 "Are 'Mestizos' Hybrids? The Conceptual Politics of Andean Identities". Journal of Latin American Studies 37 (2): 259-284.

di Salvia, Daniela

2011 "Para una dialéctica de la naturaleza andina: Aproximaciones filosófico-antropológicas a las creencias quechuas en los Apus y la Pachamama". Gazeta de Antropología 27 (1): artículo 13. http://hdl.handle.net/10481/15373.

Endere, María Luz

2000 "Patrimonios en disputa: Acervos nacionales, investigación arqueológica y reclamos étnicos sobre restos humanos". Trabajos de Prehistoria 57(1): 5-17. http:// tp.revistas.csic.es/index.php/tp/article/view/258/258.

García Canclini, Néstor

1999 "Los usos sociales del patrimonio cultural". En Patrimonio etnológico: Nuevas perspectivas de estudio, por Encarnación Aguilar Criado. Andalucía, España: Junta de Andalucía, Consejería de Cultura.

Gnecco, Cristóbal

1999 Multivocalidad histórica: Hacia una cartografía poscolonial de la arqueología. Bogotá: Corcas Editores.

Gnecco, Cristóbal, y Patricia Ayala

2010 “Qué hacer? Elementos para una discusión”. En Pueblos indígenas y arqueología en América Latina, compilado por Cristóbal Gnecco y Patricia Ayala. Bogotá: Fundación de Investigaciones Arqueológicas Nacionales, Banco de la República, Universidad de los Andes, Facultad de Ciencias Sociales, CESO, Ediciones Uniandes.

Haber, Alejandro

2011 "Nometodología payanesa: Notas de metodología indisciplinada". Revista de Antropología 23: 9-49.

Haber, Alejandro, y Adrián Scribano

1993 "Hacia una comprensión de la construcción científica del pasado: Ciencia y arqueología en el Noroeste argentino". Alteridades 3 (6): 39-46.

Hernández Llosas, María Isabel, Jorge Nancucheo, Mora Castro y Ramón Quinteros

2010 "Significados y usos del patrimonio arqueológico: Sobre política del conocimiento y construcción de nuevas relaciones sociales entre pueblos indígenas, sociedad, estado y ciencia". En El regreso de los muertos y las promesas del oro: Patrimonio arqueológico en conflicto, coordinado por Ivana Carina Jofré, 29-68. Córdoba, Argentina: Encuentro Grupo Editor.

Lenton, Diana

2009 'Acuerdos y tensiones, compromiso y objetividad: El 'aporte antropológico' en torno a un conflicto por territorio y recursos entre mapuches, gobiernos y capitales privados". Espacios de Crítica y Producción 40: 4-12. 


\section{Latin American Research Review}

Lifschitz, Javier Alejandro

2006 "Neocomunidades: Reconstruções de territórios e saberes". Estudos Históricos 38: 67-85.

Lombardo, Emilio

2010 "Patrimonio universal y nuevas formas de colonialidad". En Arqueología, tierras y territorios: Conflictos e intereses, compilado por Bárbara Manasse y Patricia Arenas, 203-213. Tucumán, Argentina: Lucrecia Editorial.

López, Mariel A.

2006 "Imágenes postconquista y etnogénesis en la Quebrada de Humahuaca, Jujuy, Argentina: Hipótesis de trabajo arqueológico". Memoria Americana 14: 167-202.

2012 "Miniaturas andinas como correlatos materiales del bienestar, la fertilidad y la abundancia: Jujuy, antes y después de la Colonia Temprana". Estudios Avanzados 18: 47-74.

López, Mariel, Verónica, J. Acevedo y Clara E. Mancini

2010 "Miniaturas en la fiesta/feria de Santa Ana (Quebrada de Humahuaca, Jujuy, Argentina)". En Carnavales, fiestas y ferias en el mundo andino de la Argentina, compilado por Enrique Cruz, 219-242. Salta, Argentina: Purmamarka Ediciones.

López, Mariel A., Clara E. Mancini y Gabriela Nacht

2011a "El 'Castillo de Senta' y la frontera: Continuidades y discontinuidades en el espacio, en el tiempo y entre disciplinas". Memoria Americana 19: 149-171.

$2011 b$ "Las personas, los sitios y las cosas por su nombre: Identidades y propiedades en el pueblo de Humahuaca a principios del siglo XVII". En Temas y problemas en arqueología histórica, editado por Mariano Ramos, Alicia Tapia, Fabián Bognanni, Mabel Fernández, Verónica Helfer, Carlos Landa, Matilde Lanza, Emanuel Montanari, Eugenia Néspolo y Virginia Pinau, 1:69-84. Buenos Aires, Argentina: Imprenta DOCUPRINT.

Manasse, Bárbara, y Patricia Arenas

2010a "Para empezar". En Arqueología, tierras y territorios: Conflictos e intereses, compilado por Bárbara Manasse y Patricia Arenas, 3. Tucumán, Argentina: Lucrecia Editorial.

2010b "Antropología y arqueología en contextos de nuevas luchas por la tierra". En Arqueología, tierras y territorios: Conflictos e intereses, compilado por Bárbara Manasse y Patricia Arenas, 13-52. Tucumán, Argentina: Lucrecia Editorial.

Mancini, Clara E.

2011 "La construcción de la Quebrada de Humahuaca como paisaje cultural". Seminario de Crítica 169: 17-23.

Mancini, Clara E., y Constanza Tommei

2012 "Transformaciones de la Quebrada de Humahuaca (Jujuy) en el siglo XX: Entre destino turístico y bien patrimonial". Registros 8 (9): 97-116.

Mignolo, Walter

2008 "El pensamiento des-colonial, desprendimiento y apertura: Un manifiesto". Tabula Rasa 8: 283-319.

Otero, Clarisa, Mónica Montenegro y María Clara Rivolta

2011 "Reflexiones desde la Quebrada de Humahuaca: Los museos como espacios de articulación entre la arqueología y la comunidad local". En XI Congreso Iberoamericano de Extensión Universitaria. Santa Fe, Argentina. http://www.unl.edu.ar/iberoextension /dvd/archivos/ponencias/mesa3/reflexiones-desde-la-quebrad.pdf.

Restrepo, Eduardo

2007 "Antropología y colonialidad". En El giro decolonial: Reflexiones para una diversidad epistémica más allá del capitalismo global, compilado por Santiago Castro Gómez y Ramón Grosfoguel, 289-304. Bogotá: Siglo del Hombre Editores.

Rivolta, María Clara, y Mónica Montenegro

2009 "Comunidades y práctica arqueológica en la Quebrada de Humahuaca: Representacionesyprácticasdiscursivas".Boletin GESSA.http://www.gessa-ex.es/documentos/ publicaciones/arqueologia_argentina.pdf.

Rosaldo, Renato

2011 "La narrativa en la etnografía: El imaginario asimétrico, el punto de vista y la desigualdad". En Antropología ahora, debates sobre la alteridad, compilado por Alejandro Grimson, Silvina Merenson y Gabriel Noel, 61-68. Buenos Aires: Siglo Veintiuno. 
Salas, Alberto M.

1945 El antigal de Ciénaga Grande (quebrada de Purmamarca). Buenos Aires: Publicaciones del Museo Etnográfico, serie A.

Salleras, Lucila

2011 "Territorio, turismo y desarrollo sustentable en la Quebrada de Humahuaca: Paisaje y naturaleza al servicio de la práctica turística". Estudios y Perspectivas en Turismo 20: 1123-1143.

Sánchez, Sandra

2004 "Discursos y alteridades en la Quebrada de Humahuaca (Provincia de Jujuy, Argentina): Identidad, parentesco, territorio y memoria". Boletín de Arqueología PUCP 8: 111-132.

Sánchez, Sandra, y Gabriela Sica

1992 "Algunas reflexiones acerca de los Tilcaras". Avances en Arqueología 1: 81-99.

Serrano, Antonio

1930 Los primitivos habitantes del territorio argentino. Buenos Aires: Librería y Editorial “La Facultad".

Sica, Gabriela, y Carlos Zanolli

2010 "... Para mí la historia es algo muy serio: Historia y memoria social en Purmamarca (provincia de Jujuy)". Estudios Atacameños 39: 71-84.

Svampa, Maristella

2008 "Argentina: Una cartografía de las resistencias (2003-2008)". OSAL Observatorio Social de América Latina 9 (24): 17-49.

Troncoso, Claudia A.

2009 "Patrimonio y re definición de un lugar turístico: La Quebrada de Humahuaca, provincia de Jujuy, Argentina". Estudios y Perspectivas en Turismo 18: 144-160.

Uribe Rodríguez, Mauricio, y Leonor Adán Alfaro

2003 "Arqueología, patrimonio cultural y poblaciones originarias: Reflexiones desde el desierto de Atacama". Chungará 35 (2): 295-304.

Vergara, Miguel A.

1961 Compendio de la historia de Jujuy. San Salvador de Jujuy, Argentina: Imprenta de la Provincia de Jujuy.

Zanolli, Carlos E.

2005 Tierra, encomienda e identidad: Omaguaca (1540-1638). Buenos Aires: Sociedad Argentina de Antropología.

Zecenarro Benavente, Germán

2003 "Apus tutelares y asentamientos del Cusco preinka". Boletín de Arqueología PUCP 7: 387-404. 